\title{
Lar "Doce" Lar: uma análise do consumo de açúcar e de produtos relacionados no Brasil
}

\author{
Mauricio Jorge Pinto de Souza ${ }^{1}$, Pedro Rodrigues de Oliveira $^{2}$ \\ e Heloisa Lee Burnquist ${ }^{3}$
}

\begin{abstract}
Resumo: O principal objetivo do presente trabalho é avaliar as características do consumo de açúcar e de produtos que usam açúcar em sua composição, utilizando dados das Pesquisas de Orçamentos Familiares (POF) de 2002/2003 e 2008/2009. Para tanto, foi utilizada a metodologia proposta por Hoffmann $(1983,2010)$ para a estimativa da elasticidade-renda. Os resultados mostram a significativa redução do consumo e dispêndio per capita associado ao açúcar cristal e refinado no período, bem como o aumento do consumo de açúcar na forma de produtos industrializados. Adicionalmente, a elasticidade-renda estimada para os produtos industrializados é bastante superior à do açúcar, indicando a preferência pelos consumos industrializados, associado ao processo de aumento na renda observada no período.
\end{abstract}

Palavras-chaves: Consumo de açúcar, elasticidade-renda, orçamentos familiares.

Abstract: This study evaluates the consumption characteristics of sugar and products containing sugar based on data from the Brazilian Family Budget Surveys carried out in 2002/03 and 2008/09. The methodological approach consists in estimating the income elasticities, as proposed by Hoffmann $(1983,2010)$, to capture changes in elasticities as income varies. The results show a significant reduction in per capita consumption and expenditure with crystal and refined sugar in the period, while the consumption of sugar through products containing sugar has increased. In addition, the income elasticity estimated for industrial products was much higher than for sugar, suggesting that there is a growing preference for industrial products as income increases.

Key-words: Sugar consumption, income elasticity, family budget, Brazil.

Classificação JEL: Q11, R20.

1 Professor da Universidade de São Paulo, Faculdade de Economia e Administração de Ribeirão Preto.

2 Professor da Universidade Federal da Grande Dourados (UFGD). E-mail: pedrorodrigues@ufgd.edu.br

3 Professora da Universidade de São Paulo (USP), Escola Superior de Agricultura Luiz de Queiroz (ESALQ). E-mail: hlburnqu@usp.br 


\section{Introdução}

Os padrões de consumo alimentar de diversos países, dentre eles o Brasil, têm sofrido expressivas e rápidas modificações nas últimas décadas (SARTI, CLARO e BANDONI, 2011; COELHO, AGUIAR e EALES; 2010). Essas modificações vêm sendo influenciadas pelas mudanças socioeconômicas e demográficas, tais como a urbanização, composição das famílias e o aumento da participação da mulher no mercado de trabalho (COELHO, AGUIAR e EALES; 2010; SCHLINDWEIN e KASSOUF, 2007).

Adicionalmente, observa-se um aumento do consumo de alimentos prontos fora do domicílio, o que implica na redução do consumo de alimentos tradicionais, que demandam maior tempo de preparo (SCHLINDWEIN e KASSOUF, 2007).

De acordo com Schlindwein e Kassouf (2007), no período de 1974 a 2003 ocorreu uma redução expressiva do consumo no domicílio de alimentos como o arroz polido, que teve queda de $46 \%$; o feijão, $37 \%$; o açúcar refinado, $48 \%$; o açúcar cristal, 17\%; o frango, $41 \%$. Para as autoras, parte dessa queda nas quantidades consumidas se deve à migração para o consumo de alimentos fora do domicílio. O trabalho ainda destaca o aumento significativo no período do consumo de produtos como o iogurte $(702 \%)$, o refrigerante (490\%) e alimentos preparados $(216 \%)$.
Nesse contexto de mudanças, têm ganhado importância na literatura estudos que analisam esse novo padrão de consumo das famílias (HOFFMANN, 2010; COELHO, AGUIAR e EALES, 2010; PEREDA, 2008; SCHLINDWEIN e KASSOUF, 2007; HOFFMANN, 2007; CLARO et al. 2007). Os resultados são importantes para o aperfeiçoamento das políticas públicas, bem como para a iniciativa privada associada a áreas de processamento e distribuição de alimentos.

O presente trabalho segue essa linha de análise, buscando descrever características do consumo de açúcar e de produtos que usam açúcar em sua composição utilizando dados das Pesquisas de Orçamentos Familiares (POFs) (2002/2003 e 2008/2009).

A produção de açúcar em todo o mundo dobrou desde o início da década de 1970, passando de 71 milhões de toneladas de açúcar bruto em 1971, para aproximadamente 162 milhões de toneladas na safra 2010/11. O consumo de açúcar também vem crescendo e atingiu aproximadamente 155 milhões de toneladas na safra 2010/11 (USDA, 2013). O Brasil é o maior produtor e exportador de açúcar. As Figuras 1 e 2 apresentam a evolução da produção e exportação de açúcar do Brasil entre as safras 2000/01 e 2010/11. De acordo a Unica (União da Indústria de Cana-de-açúcar), na temporada 2010/2011, foram produzidas cerca de 37,9 milhões de toneladas de 
Figura 1. Produção brasileira de açúcar por região produtora (em milhões de toneladas)

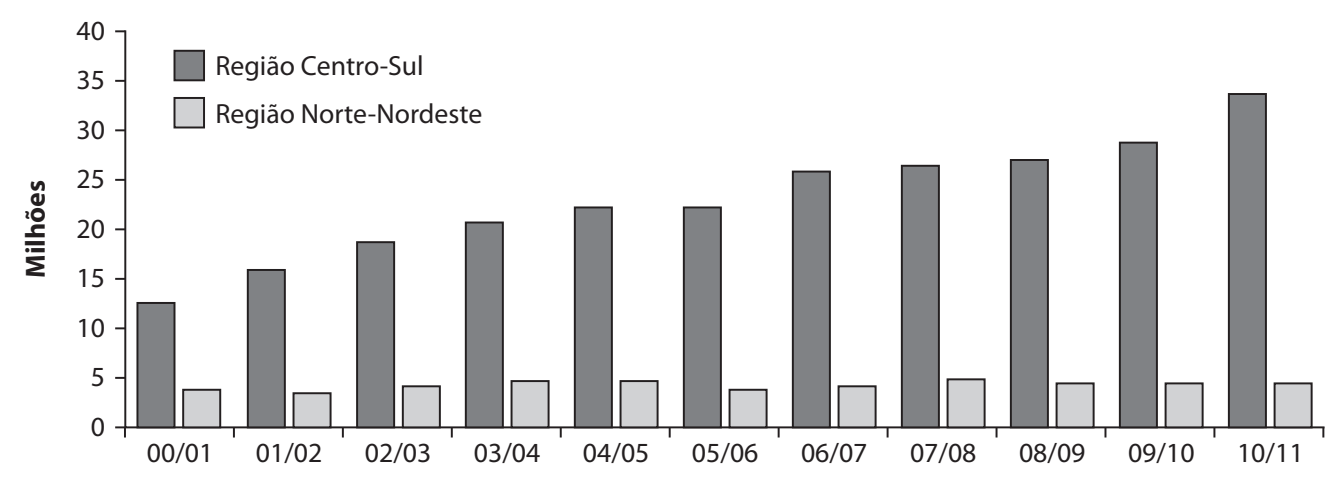

Fonte: Unica.

Figura 2. Exportações brasileiras de açúcar por região produtora (em milhões de toneladas)

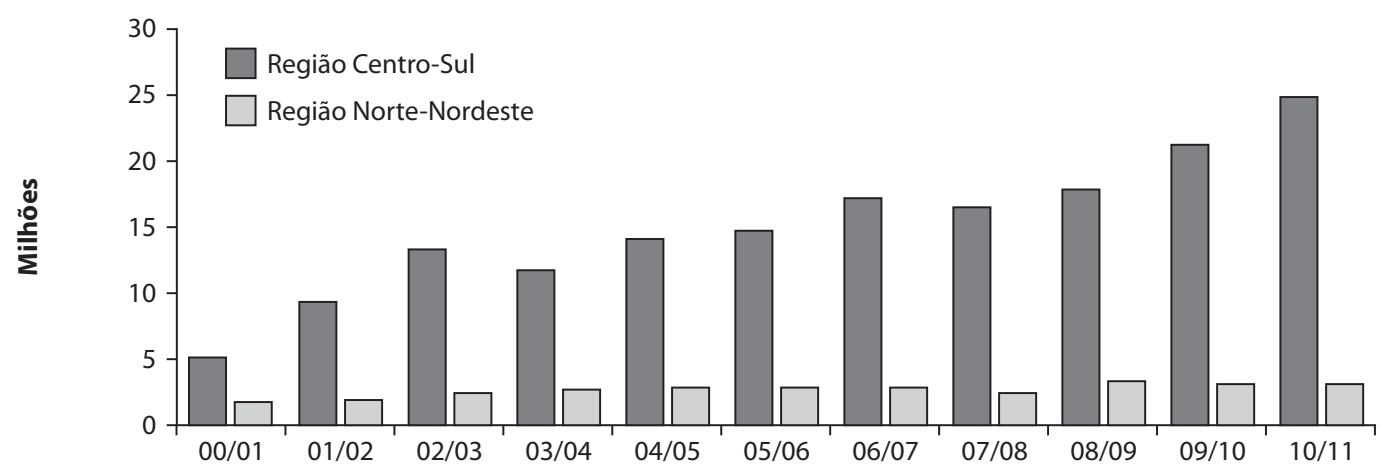

Fonte: Unica.

açúcar, sendo que aproximadamente $73 \%$ desta produção foi exportada no mesmo período.

Adicionalmente, verifica-se, das Figuras 1 e 2, que o crescimento da produção de açúcar está significativamente correlacionado com o crescimento das exportações do produto. De fato, dada a importância do setor externo, uma série de trabalhos tem focado nas características e condicionantes das exportações brasileiras de açúcar (COSTA e BURNQUIST, 2006; SILVA e BACCHI, 2005; ALVES e BACCHI, 2004). No entanto, se por um lado, a quantidade de açúcar destinada ao mercado interno não parece sofrer grandes modificações, por outro, dadas as expressivas modificações nos padrões de consumo apontadas nas últimas décadas, é possível esperar que tenha ocorrido também alterações na forma com que este açúcar destinado ao mercado interno é consumido. No que se refere à literatura, os trabalhos que avaliam características do mercado interno brasileiro de açúcar são relativamente escassos, principalmente aqueles que avaliam aspectos da demanda industrial por esse produto.

Nessa linha, o presente trabalho contribui ao avaliar não apenas as características do consumo brasileiro de açúcar refinado e cristal, mas a evolução do consumo e as elasticidades-renda associadas aos principais produtos industrializados que têm no açúcar uma importante matéria-prima. $\mathrm{O}$ conhecimento adequado das características dessa demanda permite identificar como mudanças no perfil de distribuição de renda afetam a procura por tipo de produto alimentar, facilitando o planejamento do abastecimento interno, bem como 
a formulação de políticas públicas de nutrição visando ampliar a saúde do consumidor (SARTI, CLARO e BANDONI, 2011).

Para tanto, o presente trabalho está estruturado em quatro seções. A próxima seção apresenta a metodologia e os dados utilizados. Os resultados são apresentados na seção três, enquanto que a seção quatro é destinada às considerações finais.

\section{Metodologia e dados}

Para a estimação das elasticidades-renda do dispêndio e do consumo dos produtos, é utilizada a metodologia de Hoffmann (1983, 2010), por meio de ajustamento de uma poligonal. A ideia é estimar uma elasticidade média do produto em questão, porém, a elasticidade pode ser diferente para os diferentes grupos de renda. Um bem normal para pessoas de renda mais baixa pode ser um bem inferior para pessoas de alta renda. Então, para construir uma elasticidade-renda média que seja representativa, primeiramente classificam-se as famílias conforme sua renda familiar per capita, criando dez estratos de renda per capita. Se $X_{i}, \operatorname{com} i=1, \ldots, 10$, é a renda familiar per capita média na no estrato $i$, há, portanto, nove valores dividindo as famílias segundo sua renda. Agregam-se os dez estratos $i$ em três grandes estratos (I, II, III), delimitados por $\theta_{1}$ e $\theta_{2}$, tal que no estrato I, $X \leq \theta_{1}$, no estrato II, $\theta_{1}<X$ $\leq \theta_{2}$, e no estrato III, $X>\theta_{2}$. Existem 36 formas de combinar esses dez estratos em três grandes estratos. Estima-se um modelo para cada uma das 36 combinações para cada grupo de produtos, a partir do qual se identifica o modelo com o melhor ajustamento, ou seja, com o maior $R^{2}$.

Seja $Y_{i}$ o dispêndio per capita com o produto analisado ou o consumo per capita com o mesmo, a estimativa da elasticidade-renda para cada um dos 36 modelos, considerando os três grandes estratos, é obtida com o ajustamento de uma poligonal nos logaritmos dessas variáveis, de acordo com a seguinte equação:

$\ln Y_{i}=\alpha+\beta \ln X+\sum_{h=1}^{2} \delta_{h} Z_{h i}\left(\ln X_{i}-\ln \theta_{h}\right)+u_{i}$ em que $\theta_{\mathrm{h}}$ é a renda familiar per capita correspondente ao $h$-ésimo vértice da poligonal (com $\theta_{1}<$ $\left.\theta_{2}\right), Z_{h i}$ é uma variável binária tal que $Z_{h i}=0$ para $X_{i} \leq \theta_{h}$ e $Z_{h i}=1$ para $X_{i}>\theta_{h}$ e $u_{i}$ é o termo aleatório do modelo.

Definindo as elasticidades-renda dos três grandes estratos como: $\mathrm{EI}=\beta$, EII $=\beta+\delta_{1}$, e EIII $=\beta+\delta_{1}+\delta_{2}-$ a elasticidade que é considerada neste trabalho é uma média ponderada destas três. O fator de ponderação é o porcentual do gasto/consumo com o produto no estrato em relação ao gasto/consumo total.

Os dados utilizados são os da Caderneta de Despesa das POFs de 2002-2003 e 2008-2009 para despesas dos moradores dentro e fora do domicílio. São utilizados os fatores de expansão do banco para ponderar as estimativas das poligonais pelo número de pessoas em cada estrato de renda.

A Tabela 1 mostra dados referentes à amostra nos dois períodos analisados. Os estratos de renda foram definidos conforme a Pesquisa de Orçamentos de Familiares 2002/2003. Estes, por sua vez, estão definidos desta forma em função do salário mínimo. Manteve-se a mesma estrutura para que se pudesse replicar o exercício para o período de 2008/2009. Para cada estrato mostram-se o número de pessoas, famílias e a renda média. Nota-se o aumento da população no período, mas a diminuição no tamanho médio das famílias.

Como este trabalho visa verificar a evolução da elasticidade-renda de produtos que usam açúcar em sua composição, além de açúcar cristal e refinado, foram criados alguns grupos de alimentos industrializados a partir da lista de produtos da POF: bebidas alcoólicas (alcool), balas, gomas e confeitos (bala), chocolates e cereais (choc), doces e conservas (doce), laticínios (lacteo), massas, biscoitos e panificação (massa), molhos (molhos), refrigerantes (refrigerantes), misturas secas em geral (seca), sucos e outras bebidas não alcoólicas (suco). A identificação dos principais setores industriais que demandam açúcar foi obtida em uma pesquisa de campo (survey) realizada pelo CEPEA- ESALQ/USP (2009/2010) com o setor pro- 
Tabela 1. Renda familiar per capita, número de pessoas e famílias por estrato de renda

\begin{tabular}{|c|c|c|c|c|c|c|c|c|c|c|}
\hline \multirow[b]{2}{*}{ Estrato } & \multicolumn{5}{|c|}{$2002 / 2003$} & \multicolumn{5}{|c|}{$2008 / 2009$} \\
\hline & $\begin{array}{l}\text { Classe de } \\
\text { renda per } \\
\text { capita }\end{array}$ & $\begin{array}{c}\text { Renda } \\
\text { familiar } \\
\text { per capita } \\
\text { média }\end{array}$ & $\begin{array}{l}\text { Número de } \\
\text { famílias }\end{array}$ & $\begin{array}{l}\text { Número de } \\
\text { pessoas }\end{array}$ & $\begin{array}{l}\text { Pessoas por } \\
\text { família }\end{array}$ & $\begin{array}{l}\text { Classe de } \\
\text { renda per } \\
\text { capita }\end{array}$ & $\begin{array}{c}\text { Renda } \\
\text { familiar } \\
\text { per capita } \\
\text { média }\end{array}$ & $\begin{array}{l}\text { Número de } \\
\text { famílias }\end{array}$ & $\begin{array}{l}\text { Número de } \\
\text { pessoas }\end{array}$ & $\begin{array}{l}\text { Pessoas por } \\
\text { família }\end{array}$ \\
\hline 1 & 0 a 100 & 62.9 & 6.494 .662 & 33.476 .280 & 5.15 & 0 a 140 & 92.1 & 4.354 .811 & 21.220 .402 & 4.87 \\
\hline 2 & 100 a 200 & 147.9 & 9.419 .343 & 39.376 .808 & 4.18 & 140 a 280 & 209.0 & 8.964 .905 & 37.394 .488 & 4.17 \\
\hline 3 & 200 a 400 & 286.1 & 13.015 .187 & 45.037 .828 & 3.46 & 280 a 560 & 405.1 & 15.096 .995 & 51.574 .852 & 3.42 \\
\hline 4 & 400 a 600 & 488.2 & 6.520 .394 & 20.526 .054 & 3.15 & 560 a 840 & 684.5 & 9.642 .200 & 28.525 .204 & 2.96 \\
\hline 5 & 600 a 800 & 688.2 & 3.679 .267 & 11.285 .560 & 3.07 & 840 a 1120 & 969.5 & 5.720 .140 & 15.875 .584 & 2.78 \\
\hline 6 & 800 a 1000 & 890.8 & 2.215 .130 & 6.584 .095 & 2.97 & 1120 a 1400 & 1244.2 & 3.614 .765 & 9.731 .259 & 2.69 \\
\hline 7 & 1000 a 1500 & 1210.1 & 2.919 .347 & 8.584 .270 & 2.94 & 1400 a 2100 & 1697.8 & 4.399 .155 & 11.790 .037 & 2.68 \\
\hline 8 & 1500 a 2500 & 1897.9 & 2.307 .243 & 6.469 .147 & 2.80 & 2100 a 3500 & 2689.7 & 3.258 .737 & 8.211 .656 & 2.52 \\
\hline 9 & 2500 a 4000 & 3075.2 & 1.087 .544 & 2.651 .575 & 2.44 & 3500 a 5600 & 4356.3 & 1.574 .198 & 3.748 .325 & 2.38 \\
\hline 10 & + de 4000 & 6873.7 & 876.522 & 1.854 .347 & 2.12 & + de 5600 & 9666.8 & 1.190 .700 & 2.447 .490 & 2.06 \\
\hline Total & & 500.6 & 48.534 .639 & 175.845 .964 & 3.62 & & 838.6 & 57.816 .606 & 190.519 .297 & 3.30 \\
\hline
\end{tabular}

Fonte: Elaboração própria a partir dos microdados da POF 2002/2003 e 2008/2009.

dutor de açúcar no Centro-Sul e Norte-Nordeste. Foram identificados os principais setores da indústria de alimentos para os quais se destinam as vendas de açúcar das usinas brasileiras no período da safra ${ }^{4}$. Também foram incluídos alguns produtos dietéticos na análise. Como são opções aos produtos que utilizam açúcar, a análise do dispêndio com esses produtos ajuda a entender o comportamento do consumidor no período. $\mathrm{O}$ aumento no seu consumo levaria, por um lado, à diminuição no consumo do produto tradicional e na demanda por açúcar, por conseguinte ${ }^{5}$. Foram selecionados na POF os grupos de produtos representativos: refrigerantes, sucos e chocolates.

\section{Resultados}

Essa seção apresenta os resultados referentes ao consumo e dispêndio com os grupos de alimentos e reportando as elasticidades estimadas para os grupos de alimentos selecionados.

A Tabela 2 mostra a variação no consumo e dispêndio com açúcar e com os grupos de pro-

4 A partir destes setores agregados, o presente trabalho classificou, na lista dos produtos da POF, os respectivos itens. A lista de produtos em cada grupo pode ser disponibilizada sob requisição.

5 Agradecemos a dois pareceristas anônimos por esta sugestão. dutos no período de 2002 a 2009. Nota-se queda importante no consumo per capita de açúcar e no dispêndio real com açúcar (o preço médio nominal manteve-se em um patamar próximo, considerando a inflação no período, pode-se definir que houve queda no preço real do açúcar no período). O consumo per capita de açúcar cristal caiu cerca de $35 \%$, enquanto a queda no consumo de refinado foi de aproximadamente $49 \%$. Esse resultado corrobora o de Schlindwein e Kassouf (2007), que observou queda de $48 \%$ no consumo de açúcar refinado e de $17 \%$ no de açúcar cristal no período de 1974 a 2003. Pareda (2008) também verifica redução no total de calorias adquiridas ao longo do tempo na forma de açúcar.

Por outro lado, o açúcar consumido na forma de produtos industrializados vem aumentando substancialmente. É notório na Tabela 2 o aumento no consumo de produtos como balas, gomas, confeitos, sucos, massas secas, molhos e, principalmente, doces e conservas. Esse resultado vai ao encontro aos de Schlindwein e Kassouf (2007), que observaram considerável aumento no consumo no período de 1974 a 2003 de produtos como: iogurte, refrigerante, água mineral e alimentos preparados. De acordo com essa literatura, isso é explicado pela melhoria nas condições econômicas e pelo aumento na renda per capita observadas no período, levando a um 
Tabela 2. Variações no consumo e dispêndio anuais per capita para os grupos de alimentos

\begin{tabular}{|c|c|c|c|c|c|c|c|c|c|}
\hline \multirow[b]{2}{*}{ Descrição } & \multicolumn{3}{|c|}{ POF 2002/2003 } & \multicolumn{3}{|c|}{ POF 2008/2009 } & \multicolumn{3}{|c|}{ Variação $(\%)$ no período } \\
\hline & $\begin{array}{c}\text { Consumo } \\
\text { per capita } \\
(\mathrm{kg})\end{array}$ & $\begin{array}{c}\text { Dispêndio } \\
\text { per capita } \\
(R \$)\end{array}$ & $\begin{array}{l}\text { Preço médio } \\
(R \$ \text { por } k g)\end{array}$ & $\begin{array}{c}\text { Consumo } \\
\text { per capita } \\
(\mathrm{kg})\end{array}$ & $\begin{array}{c}\text { Dispêndio } \\
\text { per capita } \\
(R \$)\end{array}$ & $\begin{array}{l}\text { Preço médio } \\
(R \$ \text { por } k g)\end{array}$ & $\begin{array}{c}\text { Consumo } \\
\text { (\%) }\end{array}$ & $\begin{array}{c}\text { Dispêndio } \\
(\%)\end{array}$ & $\begin{array}{c}\text { Preço } \\
(\%)\end{array}$ \\
\hline Açúcar cristal & 12,19 & 13,05 & 1,07 & 7,94 & 7,78 & 0,98 & $-34,68$ & $-40,43$ & $-8,55$ \\
\hline Açúcar refinado & 6,12 & 7,79 & 1,27 & 3,14 & 3,48 & 1,11 & $-48,69$ & $-55,40$ & $-13,08$ \\
\hline Álcool & 4,97 & 13,14 & 2,64 & 5,89 & 20,84 & 3,54 & 18,49 & 58,60 & 33,85 \\
\hline Bala & 0,15 & 1,15 & 7,69 & 0,22 & 1,92 & 8,61 & 48,93 & 66,84 & 12,03 \\
\hline Choc & 1,65 & 12,34 & 7,48 & 1,42 & 13,98 & 9,85 & $-13,94$ & 13,29 & 31,64 \\
\hline Doce & 0,75 & 3,63 & 4,81 & 8,63 & 19,88 & 2,30 & 1044,56 & 447,66 & $-52,15$ \\
\hline Lacteos & 4,27 & 16,13 & 3,78 & 4,40 & 21,24 & 4,83 & 2,95 & 31,68 & 27,91 \\
\hline Massas & 5,70 & 27,00 & 4,73 & 5,99 & 38,23 & 6,38 & 5,01 & 41,59 & 34,84 \\
\hline Molho & 0,42 & 1,63 & 3,83 & 0,65 & 3,00 & 4,64 & 52,20 & 84,48 & 21,21 \\
\hline Refrigerante & 23,97 & 20,95 & 0,87 & 23,53 & 32,29 & 1,37 & $-1,83$ & 54,11 & 56,99 \\
\hline Seca & 0,59 & 4,38 & 7,48 & 1,49 & 12,58 & 8,42 & 155,25 & 187,21 & 12,52 \\
\hline Suco & 1,11 & 3,43 & 3,10 & 1,48 & 4,94 & 3,33 & 33,75 & 43,96 & 7,63 \\
\hline Adoçantes & - & 0,65 & - & - & 0,83 & - & - & 27,86 & - \\
\hline Sucos diet & - & - & - & 0,05 & 0,16 & 2,96 & - & - & - \\
\hline Refrigerantes diet & - & - & - & 1,15 & 1,70 & 1,48 & - & - & - \\
\hline Chocolates diet & - & - & - & 0,00 & 0,12 & 26,23 & - & - & - \\
\hline
\end{tabular}

Fonte: Elaboração própria a partir dos microdados da POF.

incremento no consumo de produtos com maior valor agregado e mais industrializados.

Os produtos dietéticos, por sua vez, aparecem desagregados dos produtos tradicionais somente na POF mais recente. Em 2002-2003 observou-se somente o consumo de adoçantes e não de sucos, chocolates e refrigerantes dietéticos. No entanto, optou-se por não incluir o consumo per capita dos adoçantes por haver adoçantes líquidos e em pó, o que distorceria a unidade de medida.

São notados, na Tabela 2, os sucos diet com baixo consumo per capita e o preço médio menor que o dos sucos normais. Na verdade, o número de observações é relativamente pequeno para este grupo de produtos. O mesmo acontece para os chocolates diet. $\mathrm{O}$ alto preço médio por $\mathrm{kg}$ do chocolate diet pode ser um indicativo do baixo consumo e, consequentemente, das poucas observações. O dispêndio com adoçantes, por outro lado, apresentou leve aumento no período. Todavia, o consumo de produtos dietéticos, em função da sua magnitude, não parece ter influenciado a queda no consumo de açúcar no período. Os dados da POF não permitem esta conclusão, uma vez que o consumo destes produtos é pequeno. O efeito que parece prevalecer é o de migração do consumo de açúcar in natura para o açúcar contido em produtos industrializados.

A Tabela 3 apresenta a elasticidade-renda média do consumo e do dispêndio para o esquema ótimo de agregação das classes de renda per capita em três estratos. De maneira geral, não houve grandes divergências na elasticidade-renda média estimada entre as 36 combinações. $\mathrm{O}$ coeficiente de determinação $\left(R^{2}\right)$ também foi elevado para todos os modelos ${ }^{6}$.

Todos os grupos apresentam demanda inelástica, mostrando que aumentos porcentuais na renda transformam-se em aumentos porcentuais menores no consumo ou dispêndio, à exceção do grupo de sucos prontos e outras bebidas não alcoólicas e de refrigerantes dietéticos que, tanto para

\footnotetext{
6 Quando comparados aos valores de Hoffmann (2010) são observadas diferenças nas elasticidades estimadas para grupos de produtos semelhantes. Isto se deve, basicamente, à escolha dos produtos que compõem cada grupo. Isto ocorre mesmo para grupos supostamente homogêneos como, por exemplo, 'açúcar refinado'. A POF inclui diversos tipos de produtos semelhantes e o modo de agregá-los poderá ser diferente em cada trabalho.
} 
Tabela 3. Elasticidade-renda média do consumo e do dispêndio estimada para diferentes grupos de alimentos

\begin{tabular}{|c|c|c|c|c|c|c|c|c|}
\hline \multirow{3}{*}{$\begin{array}{l}\text { Grupos de } \\
\text { alimentos }\end{array}$} & \multicolumn{4}{|c|}{2002} & \multicolumn{4}{|c|}{2008} \\
\hline & \multicolumn{2}{|c|}{ Consumo } & \multicolumn{2}{|c|}{ Dispêndio } & \multicolumn{2}{|c|}{ Consumo } & \multicolumn{2}{|c|}{ Dispêndio } \\
\hline & $\begin{array}{l}\text { Elast. } \\
\text { média }\end{array}$ & $\begin{array}{c}\text { Esquema } \\
\text { ótimo }\end{array}$ & $\begin{array}{l}\text { Elast. } \\
\text { média }\end{array}$ & $\begin{array}{c}\text { Esquema } \\
\text { ótimo }\end{array}$ & $\begin{array}{l}\text { Elast. } \\
\text { média }\end{array}$ & $\begin{array}{c}\text { Esquema } \\
\text { ótimo }\end{array}$ & $\begin{array}{l}\text { Elast. } \\
\text { média }\end{array}$ & $\begin{array}{c}\text { Esquema } \\
\text { ótimo }\end{array}$ \\
\hline Açúcar cristal & $-0,08$ & $2-6-2$ & $-0,12$ & $2-6-2$ & 0,11 & $1-1-8$ & 0,10 & $1-1-8$ \\
\hline Açúcar refinado & 0,17 & $2-2-6$ & 0,16 & $2-2-6$ & 0,18 & $6-2-2$ & 0,16 & $6-1-3$ \\
\hline Álcool & 0,78 & $3-3-4$ & 0,79 & $3-4-3$ & 0,79 & $3-6-1$ & 0,80 & $4-5-1$ \\
\hline Bala & 0,45 & $1-3-6$ & 0,59 & $1-1-8$ & 0,53 & $5-1-4$ & 0,66 & $3-3-4$ \\
\hline Choc & 0,40 & $6-1-3$ & 0,66 & $1-7-2$ & 0,34 & $4-2-4$ & 0,71 & $3-3-4$ \\
\hline Doce & 0,40 & $1-1-8$ & 0,69 & $1-7-2$ & 0,40 & $1-3-6$ & 0,41 & $1-2-7$ \\
\hline Lacteos & 0,72 & $3-5-2$ & 0,76 & $3-4-3$ & 0,62 & $2-5-3$ & 0,67 & $2-5-3$ \\
\hline Massas & 0,24 & $1-4-5$ & 0,40 & $1-2-7$ & 0,27 & $5-2-3$ & 0,38 & $3-4-3$ \\
\hline Molho & 0,78 & $1-6-3$ & 0,79 & $1-6-3$ & 0,69 & $1-5-4$ & 0,74 & $2-5-3$ \\
\hline Refrigerante & 0,52 & 3-3-4 & 0,57 & $3-3-4$ & 0,48 & $3-3-4$ & 0,51 & $3-4-3$ \\
\hline Seca & 0,59 & $1-2-7$ & 0,61 & $4-5-1$ & 0,36 & $1-3-6$ & 0,45 & $5-3-2$ \\
\hline Suco & 1,14 & $1-1-8$ & 1,08 & $2-2-6$ & 1,00 & $3-5-2$ & 1,04 & $3-5-2$ \\
\hline Adoçantes & - & - & 0,93 & $2-1-7$ & - & - & 0,94 & $1-1-8$ \\
\hline Sucos diet & - & - & - & - & 2,24 & $2-3-5$ & 2,30 & $3-2-5$ \\
\hline Refrigerantes diet & - & - & - & - & 1,10 & $1-4-5$ & 1,14 & $1-4-5$ \\
\hline Chocolates diet & - & - & - & - & 1,09 & $5-1-4$ & 1,23 & $5-1-4$ \\
\hline
\end{tabular}

Nota: “Esquema ótimo" se refere à combinação dos dez estratos em três grandes estratos que gerou o maior $\mathrm{R}^{2}$.

Fonte: Elaboração própria a partir dos microdados da POF.

consumo quanto para o dispêndio, mostraram-se bens superiores.

Os grupos de alimentos apresentaram, de maneira geral, elasticidade parecida nos dois períodos, revelando preferências relativamente estáveis. Chama a atenção, porém, a elasticidade negativa para o açúcar cristal em 2002 e que se tornou elasticidade positiva em 2008, passando de bem inferior em um período para bem normal no seguinte. Esse resultado corrobora os encontrados por Coelho, Aguiar e Eales (2010). Os autores estimaram um sistema de demanda utilizando dados da POF (2002/2004) e verificaram que um aumento na renda familiar provoca diminuição na probabilidade do consumo de produtos como o arroz e o açúcar.

Ainda da Tabela 3, verifica-se que a elasticidade-renda pelos produtos industrializados é bastante superior à do açúcar. Isto novamente revela a preferência dos consumidores pelos produtos industrializados, associada ao processo de aumento na renda observada no período.
A Tabela 4 complementa a análise e mostra o consumo e dispêndio por grupos de produtos, separados por região brasileira7. Algumas diferenças regionais no consumo dos bens merecem ser discutidas. Nota-se o baixo consumo de açúcar refinado no Centro-Oeste nos dois períodos. O consumo per capita de bebidas alcoólicas é bem maior no Centro-Oeste, Sul e Sudeste que no Norte e Nordeste. No consumo de molhos prontos, a região Sudeste se destaca em relação às outras, apresentando consumo relativamente superior. Verifica-se também baixo consumo de laticínios no Norte e no Nordeste. No Norte, uma possível causa é o elevado preço médio desses bens. Por outro lado, no Nordeste, o preço dos laticínios é até mais baixo em relação ao prevalecente em outras regiões, como na Centro-Oeste, por exemplo. No Nordeste, os preços médios dos chocolates e cereais também são inferiores

7 Para não comprometer a representatividade das estimativas, a separação por região para os produtos dietéticos não é apresentada. 
Tabela 4. Consumo e dispêndio anuais per capita por região brasileira

\begin{tabular}{|c|c|c|c|c|c|c|c|c|c|c|c|c|c|c|c|}
\hline \multicolumn{16}{|c|}{ POF 2002/2003 } \\
\hline \multirow{2}{*}{ Descrição } & \multicolumn{3}{|c|}{ Norte } & \multicolumn{3}{|c|}{ Nordeste } & \multicolumn{3}{|c|}{ Centro-Oeste } & \multicolumn{3}{|c|}{ Sudeste } & \multicolumn{3}{|c|}{ Sul } \\
\hline & $I$ & II & III & $I$ & $I I$ & III & $I$ & $I I$ & $I I I$ & $I$ & $I I$ & III & $I$ & II & III \\
\hline Açúcar cristal & 10,44 & 12,95 & 1,24 & 14,56 & 16,59 & 1,14 & 17,14 & 18,37 & 1,07 & 11.65 & 11,39 & 0,98 & 7,83 & 8,69 & 1,11 \\
\hline Açúcar refinado & 5,92 & 8,58 & 1,45 & 4,34 & 5,44 & 1,25 & 0,77 & 0,76 & 0,99 & 7,46 & 9,30 & 1,25 & 8,25 & 10,80 & 1,31 \\
\hline Álcool & 2,03 & 6,82 & 3,37 & 2,05 & 5,25 & 2,56 & 5,40 & 15,95 & 2,95 & 6,69 & 17,55 & 2,62 & 6,89 & 17,38 & 2,52 \\
\hline Bala & 0,04 & 0,36 & 8,62 & 0,04 & 0,32 & 7,67 & 0,11 & 0,81 & 7,18 & 0,17 & 1,60 & 9,55 & 0,38 & 2,03 & 5,37 \\
\hline Choc & 0,88 & 6,46 & 7,32 & 1,60 & 7,71 & 4,81 & 0,99 & 8,06 & 8,16 & 1,94 & 16,12 & 8,31 & 1,67 & 15,30 & 9,14 \\
\hline Doce & 0,51 & 1,74 & 3,41 & 0,81 & 2,50 & 3,08 & 0,58 & 3,05 & 5,28 & 0,65 & 3,98 & 6,08 & 1,14 & 6,09 & 5,32 \\
\hline Lacteos & 1,37 & 7,00 & 5,12 & 2,04 & 7,71 & 3,78 & 2,89 & 12,05 & 4,17 & 6,10 & 22,87 & 3,75 & 5,41 & 19,37 & 3,58 \\
\hline Massas & 3,98 & 18,26 & 4,59 & 6,68 & 23,97 & 3,59 & 3,49 & 17,81 & 5,10 & 5,53 & 30,71 & 5,55 & 6,31 & 30,99 & 4,91 \\
\hline Molho & 0,11 & 0,47 & 4,27 & 0,16 & 0,76 & 4,65 & 0,16 & 0,78 & 4,86 & 0,73 & 2,61 & 3,59 & 0,34 & 1,45 & 4,28 \\
\hline Refrigerante & 14,15 & 14,69 & 1,04 & 12,27 & 11,09 & 0,90 & 22,24 & 20,68 & 0,93 & 30,80 & 26,83 & 0,87 & 32,39 & 26,07 & 0,81 \\
\hline Seca & 0,32 & 2,35 & 7,36 & 0,24 & 1,53 & 6,39 & 0,49 & 3,83 & 7,81 & 0,77 & 5,83 & 7,58 & 0,90 & 6,98 & 7,79 \\
\hline Suco & 0,56 & 1,41 & 2,52 & 0,29 & 0,87 & 2,99 & 0,83 & 2,45 & 2,94 & 1,75 & 5,65 & 3,23 & 1,23 & 3,42 & 2,77 \\
\hline \multicolumn{16}{|c|}{ POF 2008/2009 } \\
\hline \multirow{2}{*}{ Descrição } & \multicolumn{3}{|c|}{ Norte } & \multicolumn{3}{|c|}{ Nordeste } & \multicolumn{3}{|c|}{ Centro-Oeste } & \multicolumn{3}{|c|}{ Sudeste } & \multicolumn{3}{|c|}{ Sul } \\
\hline & $I$ & II & III & $I$ & II & $I I I$ & $I$ & II & III & $I$ & II & $I I I$ & $I$ & $I I$ & $I I I$ \\
\hline Açúcar cristal & 7,36 & 8,26 & 1,12 & 6,11 & 6,28 & 1,03 & 11,70 & 11,19 & 0,96 & 8,48 & 7,87 & 0,93 & 8,39 & 8,43 & 1,01 \\
\hline Açúcar refinado & 3,36 & 4,46 & 1,33 & 1,98 & 2,05 & 1,03 & 0,41 & 0,46 & 1,12 & 3,86 & 4,22 & 1,09 & 4,54 & 5,05 & 1,11 \\
\hline Álcool & 3,35 & 13,75 & 4,11 & 2,67 & 9,94 & 3,72 & 6,31 & 23,36 & 3,70 & 7,36 & 25,25 & 3,43 & 9,11 & 31,94 & 3,50 \\
\hline Bala & 0,10 & 0,92 & 8,93 & 0,07 & 0,61 & 8,31 & 0,19 & 1,58 & 8,37 & 0,26 & 2,21 & 8,60 & 0,50 & 4,34 & 8,72 \\
\hline Choc & 0,78 & 7,60 & 9,69 & 2,11 & 10,38 & 4,92 & 1,00 & 10,01 & 10,05 & 1,15 & 15,71 & 13,71 & 1,44 & 21,54 & 15,00 \\
\hline Doce & 6,43 & 19,74 & 3,07 & 8,42 & 18,58 & 2,21 & 9,68 & 23,95 & 2,47 & 8,84 & 19,91 & 2,25 & 9,09 & 20,35 & 2,24 \\
\hline Lacteos & 2,53 & 14,18 & 5,60 & 3,00 & 13,46 & 4,49 & 4,06 & 19,91 & 4,90 & 4,99 & 25,06 & 5,02 & 6,58 & 29,92 & 4,55 \\
\hline Massas & 4,92 & 30,91 & 6,28 & 6,50 & 34,45 & 5,30 & 4,15 & 27,89 & 6,73 & 5,76 & 39,54 & 6,87 & 7,18 & 51,06 & 7,11 \\
\hline Molho & 0,17 & 0,98 & 5,66 & 0,23 & 1,16 & 5,04 & 0,44 & 2,39 & 5,43 & 1,08 & 4,80 & 4,42 & 0,55 & 2,85 & 5,18 \\
\hline Refrigerante & 19,08 & 30,01 & 1,57 & 13,19 & 18,35 & 1,39 & 22,06 & 32,89 & 1,49 & 27,94 & 37,34 & 1,34 & 34,11 & 45,70 & 1,34 \\
\hline Seca & 1,27 & 10,41 & 8,23 & 0,90 & 6,85 & 7,58 & 1,63 & 12,84 & 7,89 & 1,69 & 14,63 & 8,64 & 2,13 & 18,87 & 8,88 \\
\hline Suco & 1,06 & 2,96 & 2,78 & 0,59 & 1,80 & 3,06 & 1,66 & 5,41 & 3,25 & 2,10 & 7,31 & 3,47 & 1,56 & 5,06 & 3,24 \\
\hline
\end{tabular}

Notas: I: Consumo per capita (kg), II: Dispêndio per capita (R\$), III: preço médio praticado.

Fonte: POF 2002/2003 e 2008/2009.

comparados aos observados nas demais regiões brasileiras.

Uma mudança ocorrida no período aconteceu com o consumo de refrigerantes. O consumo era baixo no Norte e Nordeste em 2002/2003, porém, em 2008/2009, apenas o Nordeste manteve o baixo consumo. A expansão do consumo na região Norte no período foi de aproximadamente $35 \%$. O consumo de sucos também teve expansão importante no período. Concentrada no Sul e Sudeste em 2002/2003, o consumo per capita destes dobrou no período nas regiões
Norte, Nordeste e Centro-Oeste - com expansão moderada no Sul e Sudeste.

\section{Conclusões}

As mudanças socioeconômicas e demográficas ocorridas no Brasil nas últimas décadas têm provocado importantes modificações nos padrões de consumo alimentar, aumentando a relevância de estudos que avaliam aspectos desse novo padrão de consumo das famílias. 
O presente trabalho avalia os padrões de demanda brasileiros por açúcar refinado e cristal e também por produtos industrializados, que usam açúcar em sua composição em termos de consumo per capita e elasticidade, além de produtos substitutos, como os dietéticos. Os resultados encontrados mostram que, apesar da diminuição no consumo direto de açúcar, aumentou o consumo da commodity na forma de produtos industrializados, que, por sua vez, tiveram significativa expansão no período. Esses resultados reforçam os trabalhos que evidenciam o aumento do consumo de alimentos fora do domicílio, de alimentos prontos, e a substituição do consumo de alimentos tradicionais.

Adicionalmente, as elasticidades-renda estimadas para o açúcar cristal e refinado apresentaram valores relativamente baixos quando comparados com as elasticidades médias estimadas para os grupos de produtos industrializados. Novamente, isso confirma a evidência de preferência dos consumidores por prontos/ industrializados.

Os resultados também indicam uma importante heterogeneidade regional tanto em termos do consumo e despesa de açúcar cristal e refinado como de produtos industrializados. Os diferentes níveis de renda em que se encontram as regiões implicam que o consumo de açúcar e de bens industrializados que utilizam açúcar em sua composição crescerá de forma diferente. Uma vez que o crescimento da renda leva as pessoas a mudarem seu padrão de consumo - preferindo bens industrializados - e bens que se mostram normais para uma faixa de renda baixa, chegam até a se mostrar inferiores para faixas de renda mais elevadas, é de se esperar que este padrão de diminuição do consumo per capita de açúcar e aumento no consumo de produtos industrializados que levam açúcar em sua composição continue, principalmente nas regiões Norte e Nordeste - onde o consumo de produtos industrializados se mostrou menor.

Desta forma, a queda observada no consumo de açúcar desde a década de 1970, e que continua em vigência, não significa necessariamente uma preocupação para o setor, uma vez que ele continua sendo consumido no mercado interno sob a forma de produtos industrializados. Por outro lado, como mudanças no padrão alimentar são consideradas causas centrais do aumento nas taxas de obesidade e doenças crônicas mundialmente, essa elevação no consumo de produtos industrializados derivada dos ganhos de renda ocorrido na última década merece atenção das políticas públicas de nutrição.

\section{Referências bibliográficas}

ALVES, L. R. A. e BACCHI, M. R. P. Oferta de exportação de açúcar do Brasil. Revista de Economia e Sociologia Rural, Brasília, v. 42, n. 01, 2004.

CLARO, R. M., CARMO, H. C. E., MACHADO, F. M. S. e MONTEIRO, C. A. Renda, preço dos alimentos e participação de frutas e hortaliças na dieta. Revista Saúde Pública, v. 41, p. 557-64, 2007.

COELHO, A. B., AGUIAR, D. R. D. e EALES, J. S. Food Demand in Brazil: An Application of Shonkwiler \& Yen Two-Step Estimation Method. Estudos Econômicos (USP. Impresso), v. 40, p. 185-211, 2010.

COSTA, C. C. e BURNQUIST, H. L. O subsídio cruzado às exportações de açúcar da União Européia: Impactos sobre as exportações brasileiras. Revista de Economia Aplicada, São Paulo, v. 10, n. 1, p. 91-109, 2006.

HOFFMANN, R. Elasticidades de Engel para dispêndios familiares na cidade do Rio de Janeiro: outro método de estimação. Pesquisa e Planejamento Econômico, Rio de Janeiro, v. 13, n. 1, p. 267-274, 1983

. Elasticidade-renda das despesas e do consumo de alimentos no Brasil em 2002-2003. In: SILVEIRA, F. G. et al. (Org.). Gasto e consumo das famílias brasileiras contemporâneas. Vol. 2. Brasília: IPEA, 2007, p. 463-483.

- Estimativas das elasticidades-renda de várias categorias de despesa e de consumo, especialmente alimentos, no Brasil, com base na POF de 2008-2009. Revista de Economia Agrícola (Impresso), v. 57, p. 49-62, 2010.

PEREDA, P. C. Estimação das equações de demanda por nutrientes usando o modelo QuadraticAlmost Ideal Demand System (QUAIDS). Dissertação (Mestrado) - Faculdade de Economia, Administração e Contabilidade, Universidade de São Paulo, São Paulo, 2008.

SARTI, F. M., CLARO, R. M. e BANDONI, D. H. Contribuições de estudos sobre demanda de alimentos à 
formulação de políticas públicas de nutrição. Cad. Saúde Pública, Rio de Janeiro, v. 27, n. 4, p. 639-647, abr. 2011.

SCHLINDWEIN, M. M. e KASSOUF, A. L. Mudanças no padrão de consumo de alimentos tempo-intensivos e de alimentos poupadores de tempo, por região no Brasil. In: SILVEIRA, F. G., SERVO, L. M. S., MENEZES, T. e PIOLA, S. F. (Org.). Gasto e consumo das famílias brasileiras contemporâneas. Vol. 2. Brasília: IPEA Instituto de Pesquisa Econômica Aplicada, 2007, p. $423-462$
SILVA, M. V. S. E. e BACCHI, M. R. P. Condicionantes das exportações brasileiras de açúcar bruto. Agricultura em São Paulo, São Paulo, v. 52, n. 2, p. 99-110, 2005.

UNICA. União da Indústria de Cana-de-açúcar Estatísticas. Disponível em: <http://www.unica.com. br/dadosCotacao/estatistica/> . Acesso em: 23 mar. 2012. USDA. Sugar: World Markets and Trade. Disponível em: $<w w w . f a s . u s d a . g o v / p s d o n l i n e / c i r c u l a r s / s u g a r . p d f>$. Acesso em: $19 \mathrm{dez} .2013$. 
O Maurício contagiou a todos os que com ele conviveram, com uma forma diferente de energia. Dotado de uma inteligência privilegiada, que compartilhava com generosidade, rapidamente conquistou muitos amigos durante os anos que passou em Piracicaba, e depois em Ribeirão Preto. E foram esses amigos que o viram evoluir e amadurecer em seu trabalho, em suas atitudes e relações pessoais, sempre agindo com coragem para defender suas opiniões e, principalmente, mantendo atitudes éticas impecáveis.

Tive o privilégio de acompanhar a facilidade que ele tinha para aprender novos conceitos, desde que iniciou o mestrado, esbanjando criatividade nas aplicações. Sem dúvida, foi uma fase em que trabalhar em um projeto conjunto tornou-se muito divertido, combinando as discussões com as descobertas. Foi a época em que adotamos o lema: "quanto mais você divide uma ideia, maior e mais robusta ela fica".

E foi ele também quem me ensinou que não devemos nos revoltar quando temos que lidar com algo que (ainda) não entendemos. Não podemos parar de tentar!! É uma forma de perpetuarmos o objetivo de um grande amigo que contribuiu, em muito, para deixar um mundo melhor; que realmente fez uma grande diferença na vida de muita gente!

Heloisa Lee Burnquist

Normalmente, a publicação de um trabalho envolve comemoração. Mas este não é exatamente o caso. Perdemos nosso amigo Maurício alguns dias após o envio dos ajustes finais.

Pude trabalhar algumas vezes com ele. Mas é sobre outro aspecto que gostaria de fazer meu relato: a perda do meu amigo.

É difícil processar a notícia de seu falecimento - em uma situação cotidiana, totalmente inesperada. Sei que eu não fui o único que chorou durante dias. Mesmo agora, já passados alguns meses do ocorrido, lembranças sempre vêm à mente. Conversando com outros amigos em comum percebi o quanto, mesmo após o final do período em Piracicaba, o Maurício se fazia presente na vida de seus amigos.

Eu nunca o vi triste. Já o vi preocupado, atarefado, apreensivo, mas nunca triste. Além disso, e sei que posso falar por muitos neste ponto, o Maurício nos proporcionava momentos hilários. E tenho certeza que é assim que sempre vamos nos lembrar dele: com alegria, com festa, com bons momentos. E é por isso que é tão difícil a sua perda. Porque apesar de já termos passado vários bons momentos com ele, sabíamos que o que ainda estava por vir também seria muito bom. É a viagem que não vai acontecer, é a festa que não vamos mais, é a conversa que não teremos. Esse é o sentimento maior da sua perda. É a perda do porvir.

Profissionalmente, o Maurício tinha um futuro brilhante. Além de muito inteligente, era muito determinado. Todos nós perdemos uma ótima pessoa, um ótimo colega de trabalho, mas eu perdi, sobretudo, um grande amigo - do qual sempre sentirei muita falta. 
